\title{
Biodegradation of variable-chain-length $n$-alkanes in Rhodococcus opacus R7 and the involvement of an alkane hydroxylase system in the metabolism
}

\author{
Jessica Zampolli, ${ }^{1,2}$ Elena Collina², Marina Lasagni² and Patrizia Di Gennaro ${ }^{*}$
}

\begin{abstract}
Rhodococcus opacus R7 is a Gram-positive bacterium isolated from a polycyclic aromatic hydrocarbon contaminated soil for its versatile metabolism; indeed the strain is able to grow on naphthalene, o-xylene, and several long- and medium-chain $n$-alkanes. In this work we determined the degradation of $n$-alkanes in Rhodococcus opacus R7 in presence of $n$-dodecane (C12), n-hexadecane (C16), n-eicosane (C20), n-tetracosane (C24) and the metabolic pathway in presence of C12. The consumption rate of C12 was 88\%, of C16 was $69 \%$, of C20 was $51 \%$ and of C24 it was $78 \%$. The decrement of the degradation rate seems to be correlated to the length of the aliphatic chain of these hydrocarbons. On the basis of the metabolic intermediates determined by the R7 growth on C12, our data indicated that $R$. opacus R7 metabolizes medium-chain $n$-alkanes by the primary alcohol formation. This represents a difference in comparison with other Rhodococcus strains, in which a mixture of the two alcohols was observed. By GC-MSD analysis we also identified the monocarboxylic acid, confirming the terminal oxidation.

Moreover, the alkB gene cluster from R. opacus R7 was isolated and its involvement in the $n$-alkane degradation system was investigated by the cloning of this genomic region into a shuttle-vector $E$. coli-Rhodococcus to evaluate the alkane hydroxylase activity. Our results showed an increased biodegradation of $\mathrm{C} 12$ in the recombinant strain R. erythropolis AP (pTipQT1-alkR7) in comparison with the wild type strain R. erythropolis AP. These data supported the involvement of the alkB gene cluster in the $n$-alkane degradation in the R7 strain.
\end{abstract}

Keywords: Rhodococcus; n-alkanes degradation; Alkane hydroxylase; AlkB; Enzymatic expression

\section{Introduction}

The problems associated with contaminated sites are assuming rising prominence in many countries (Vidali, 2001), due to the increase of anthropogenic pollution in the environment. Anthropic activities produce a wide amount of pollutants, such as aliphatic and aromatic polycyclic hydrocarbons; soil and water microorganisms can selectively degrade these xenobiotic compounds as the only carbon and energy source. The knowledge of the metabolic pathways of these microorganisms allows the reclamation of polluted sites. There are a lot of studies on the metabolism of these compounds in Gramnegative bacteria while Gram-positive bacteria have not

\footnotetext{
* Correspondence: patrizia.digennaro@unimib.it

'Department of Biotechnology and Biosciences, University of Milano-Bicocca, Piazza della Scienza 2, 20126 Milano, Italy

Full list of author information is available at the end of the article
}

been investigated to the same extent. Members of the Rhodococcus genus, found in many environmental niches, have a marked ability to metabolize a wide variety of xenobiotic compounds, and it is well recognized that species of this genus are key participants in the recycling of complex organic compounds (Finnerty, 1992; Larkin et al., 2005; Martínková et al., 2009). The genetic rearrangement and plasticity of the Rhodococcus genome have appeared to play a significant role in its adaptation to a wide variety of environmental contaminants (Leahy and Colwell, 1990; Van der Meer et al., 1992; Kulakov et al., 1998; Larkin et al., 2006; McLeod et al., 2006).

Alkane degraders are bacteria that have a very versatile metabolism, so that they can use as carbon source many other compounds in addition to alkanes (Smits et al., 2002; Margesin et al., 2003; Harayama et al., 2004). The ability of these bacteria of degrading $n$-alkanes is well

\section{实}


established, but relatively little is known about the molecular characteristics of their alkane-degradative systems.

Alkanes are saturated, linear molecules whose chain length can vary from 1 (in methane) to more than 50 carbon atoms. They are the major components of petroleum fuels which can be commonly found in contaminated environments (So and Young, 1999), indeed they constitute about $20-50 \%$ of crude oil, depending on the source of the oil. In addition, alkanes (predominantly long-chain compounds) are produced throughout the biosphere by living organisms (plants, algae and bacteria) as a waste product, a structural element, a defense mechanism, or as a chemoattractant (van Beilen et al., 2003). The aerobic degradation of these molecules starts by oxidation of one of the terminal methyl groups to generate the corresponding primary alcohol by alkane hydroxylases (AHs). The oxidation can occur on various positions: terminal or subterminal, to final conversion to a fatty acid (van Beilen et al., 2003; Ji et al., 2013). So far some alkane-degradative systems of a small number of Gram-negative bacteria have been well characterized, such as those of Alkanivorax, Pseudomonas and Acinetobacter (Alonso and Roujeinikova, 2012; Ratajczak et al., 1998; van Beilen and Funhoff, 2007; Wang and Shao, 2013). The alk system found in Pseudomonas putida GPo1, which degrades $n$-alkanes from $n$-pentane to $n$-dodecane, remains the most extensively characterized alkane hydroxylase system. It is a three-component alkane hydroxylase complex consisting of a particulate nonheme integral membrane alkane monooxygenase $(\mathrm{AlkB})$ and two soluble proteins, rubredoxin (AlkG) and rubredoxin reductase (AlkT) (Alonso and Roujeinikova, 2012).

Much less is known about the alkane-degradative systems of Gram-positive bacteria. Homologs of alkB gene were amplified from psychrotrophic Rhodococcus sp. Q15 (Whyte et al., 2002), Gordonia sp. strain SoCg (Lo Piccolo et al., 2011) and Rhodococcus opacus B4 (Sameshima et al., 2008).

The Gordonia sp. strain SoCg unique $a l k B$ gene was analyzed by functional heterologous expression in $E$. coli and in $S$. coelicolor, which were shown to oxidize $n$-hexadecane to the correspondent primary alcohol, 1-hexadecanol, but no expression occurred in presence of long-chain $n$-triacontane. Similarly, the Rhodococcus opacus B-4 alkB1 and alkB2 genes were expressed heterologously in two $E$. coli recombinants which were able to convert $n$-alkanes ( $n$-pentane to $n$-hexadecane) to their corresponding alcohols in anhydrous organic solvents. The start codons of two genes were changed from GTG to ATG to express them in E. coli. Rhodococcus sp. strain Q15 was shown to be able to mineralize $n$-dodecane and $n$-hexadecane and bioconvert them into corresponding primary and secondary alcohols at $5^{\circ} \mathrm{C}$. The utilization of potential metabolic intermediates indicated that Q15 oxidizes alkanes by both the terminal oxidation pathway and the subterminal oxidation pathway (Whyte et al., 1998).

Rhodococcus opacus R7 is a Gram-positive bacterium isolated from a polycyclic aromatic hydrocarbon contaminated soil for its ability to grow on naphthalene. It is characterized by a versatile metabolism, indeed the strain is able to grow on naphthalene, $o$-xylene, and several long- and medium-chain $n$-alkanes. In previous studies, the genes involved in the degradation of naphthalene and $o$-xylene were identified, and the related metabolic pathways were characterized (Di Gennaro et al., 2010). In this work we determined the degradation of $n$-alkanes in Rhodococcus opacus R7, performing biodegradation kinetics in presence of $n$-dodecane (C12), $n$-hexadecane (C16), n-eicosane (C20), n-tetracosane (C24), and the metabolic pathway in presence of C12. Moreover, the $a l k B$ gene cluster from $R$. opacus $\mathrm{R} 7$ was isolated and its involvement in $n$-alkane degradation system was investigated by cloning and expression of this genomic region.

\section{Materials and methods}

Bacterial strains, growth conditions and general procedures Bacterial strains and plasmids used in this study are listed in Table 1. Rhodococcus opacus R7 (CIP 107348), isolated for its ability to grow on naphtalene and $o$-xlyene (Di Gennaro et al., 2001), was grown on M9 mineral medium (Maniatis et al., 1982), supplemented with naphthalene or $o$-xylene or different $n$-alkanes in an atmosphere saturated with these compounds, as the only carbon and energy source. Growth of R7 was performed in 100 ml-flasks with $20 \mathrm{ml}$ of $\mathrm{M} 9$ mineral medium in presence of $n$-hexane (C6), n-octane (C8), n-decane (C10), n-dodecane (C12), n-hexadecane (C16), n-eicosane (C20), n-tetracosane (C24), $n$-hexatriacontane (C36) at the concentration of $1 \mathrm{~g} / \mathrm{l}$. n-Eicosane (C20), n-tetracosane (C24), n-hexatriacontane (C36) were added in flasks as hexane solution evaporated over night or as finely ground powder.

Rhodococcus erythropolis AP, isolated in our laboratory (CIP 110799) for its ability to grow on diesel fluel (Maffei, 2004), was maintained on M9 mineral medium in a saturated atmosphere of diesel fuel at $30^{\circ} \mathrm{C}$ (Table 1). Escherichia coli $\mathrm{DH} 5 \alpha$ was grown on Luria-Bertani medium at $37^{\circ} \mathrm{C}$. To select E. coli and Rhodococcus trasformants antibiotics (ampicillin at $100 \mu \mathrm{g} / \mathrm{ml}$ for $E$. coli and tetracycline at $25 \mu \mathrm{g} / \mathrm{ml}$ for Rhodococcus) were added in the cultural medium.

Genomic DNA of $R$. opacus R7 was extracted from R7 cells as reported by Di Gennaro et al., 2010. DNA manipulation, enzymatic digests, ligation and PCR reactions were performed using standard molecular techniques (Sambrook and Russell, 1989). For recombinant plasmids extraction NucleoSpin Plasmid Kit by Machery and Nagel was used according to the manufacturer's instruction. 
Table 1 Bacterial strains and plasmids used in this study

\begin{tabular}{|c|c|c|}
\hline Strain or plasmid & Description & Reference or source \\
\hline \multicolumn{3}{|l|}{ Strains } \\
\hline Rhodococcus opacus R7 & $\begin{array}{l}\text { Long-medium-chain } n \text {-alkane degrader, alkB }{ }^{+}, \text {nar }^{+} \text {, } \\
\text { gen }^{+}, o-x y l^{+}\end{array}$ & Di Gennaro et al. 2001; Di Gennaro et al. 2010 \\
\hline Rhodococcus erythropolis AP & Diesel Fuel degrader & Maffei 2004 \\
\hline Escherichia coli DH5a & $\begin{array}{l}\left.\mathrm{d} / a c Z \Delta \mathrm{M} 15 \text {, recA1, endA1, gyrA96, thi-1, hsdR17( } \mathrm{rK}^{-}, \mathrm{mK}^{+}\right) \text {, } \\
\text { supE44, relA1, deoR, } \Delta \text { (lacZYA-argF)U169 }\end{array}$ & Promega \\
\hline Escherichia coli DH5a (pDrive-alkR7) & $\begin{array}{l}\text { E. coli } \mathrm{DH} 5 \mathrm{a} \text { containing the cloning vector pDrive, alkB } \\
\text { fragment, } \mathrm{Amp}^{r}\end{array}$ & This study \\
\hline Escherichia coli DH5a (pTipQT1-alkR7) & $\begin{array}{l}\text { E. coli DH5a containing the recombinant expression vector } \\
\text { pTipQT1, alkB fragment, Thior, Ampr }\end{array}$ & This study \\
\hline Rhodococcus erythropolis AP (pTipQT1-alkR7) & $\begin{array}{l}\text { R. erythropolis AP containing the recombinant expression } \\
\text { vector pTipQT1, alkB fragment, } T^{\prime} \mathrm{o}^{r}, \mathrm{TC}^{\mathrm{r}}\end{array}$ & This study \\
\hline \multicolumn{3}{|l|}{ plasmids } \\
\hline pDrive & E. coli cloning vector, $\mathrm{Amp}^{\mathrm{r}}$ & Qiagen \\
\hline pDrive-alkR7 & pDrive containing alkB fragment from $R$. opacus $\mathrm{R} 7$ & This study \\
\hline pTipQT1 & Shuttle-vector Amp ${ }^{r}$ E. coli - Tc' Rhodococcus spp. & Nakashima and Tamura 2004b \\
\hline pTipQT1-alkR7 & pTipQT1 containing alkB fragment from R. opacus R7 & This study \\
\hline
\end{tabular}

\section{Growth curves and $n$-alkanes biodegradation}

Growth experiments on R7 strain were performed in presence of $n$-alkanes ( $1 \mathrm{~g} / \mathrm{l})$ ranging from C6 to C36 in $20 \mathrm{ml}$ of $\mathrm{M} 9$ with $\mathrm{OD}_{600} 0.1$.

To determine $R$. opacus $\mathrm{R} 7 n$-alkanes degradation, the strain was inoculated in $20 \mathrm{ml}$ of $\mathrm{M} 9$ with $\mathrm{OD}_{600} 0.1$ and supplemented with $1 \mathrm{~g} / \mathrm{l}$ of $n$-alkanes (C12, C16, C20, C24). To determine abiotic loss, uninoculated flasks were also prepared. The flasks were incubated at $30^{\circ} \mathrm{C}$ for a maximum of $72 \mathrm{~h}$. Every $24 \mathrm{~h}$ a flask was sacrified to evaluate $n$-alkanes degradation by determination of the residual $n$-alkane by gas chromatographymass spectrometry (GC-MSD) after extraction with $n$-hexane. Bacterial growth was determined by $\mathrm{OD}_{600}$ measurements. When the strain was inoculated on $n$-alkanes with more than 16 carbon atoms, the bacteria formed clumps which included $n$-alkanes (van Beilen et al., 2002). For optical density measurements, clumps were resuspended by strong agitation.

\section{Chromatographic analyses}

Residual $n$-alkanes were extracted from the inoculated and uninoculated flasks using $n$-hexane. It occurred in $20 \mathrm{~min}$ by strong manual agitation (in test tubes), after washing of the flasks to take away any residual $n$-alkanes on their wall. The suspension was centrifuged at $4000 \mathrm{rpm}$ for $10 \mathrm{~min}$ and after $10 \mathrm{~min}$ of settling, $2 \mathrm{ml}$ were drawn from organic phase. It was conserved at $-20^{\circ} \mathrm{C}$ in vial with teflon-coated screw caps. The organic phase extracted was diluted 1:100 for GC injection. Residual $n$-alkanes were analysed by GC-MSD using a Technologies 6890 N Network GC System, interfaced with 5973 Network Mass Selective Detector (MSD) (Agilent Technologies). A ZB-5MS capillary column was used (5\% diphenyl-95\% dimethylpolysiloxane $60 \mathrm{~m}$ x $0.25 \mathrm{~mm}, 0.25 \mu \mathrm{m}$; Alltech).

Analyses were carried out in split-less injection mode using helium as carrier gas at $99.99 \%$. The injector port was set at $250^{\circ} \mathrm{C}$. The oven temperature was programmed

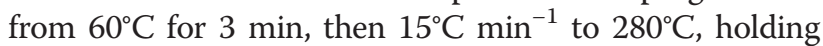
this temperature for $10 \mathrm{~min}$. Electron impact ionization spectra were obtained at $70 \mathrm{eV}$, with recording of mass spectra from $\mathrm{m} / z 42$ to $550 \mathrm{amu}$, which allows 3.5 scans $\mathrm{s}^{-1}$. All analyses were carried out with three replicates, and the mean values obtained are reported.

\section{Analysis of the metabolic intermediates from the $n$-alkane pathway}

The metabolic intermediates resulting from incubation of $R$. opacus $\mathrm{R} 7$ on $\mathrm{C} 12$ were analyzed by GC-MSD after extraction with ethyl acetate. It occurred in $20 \mathrm{~min}$ by strong manual agitation (in test tubes) in presence of $1.5 \mathrm{ml} \mathrm{HCl} 1 \mathrm{M}$. The suspension was centrifuged at $4000 \mathrm{rpm}$ for $10 \mathrm{~min}$. After centrifugation, $1.5 \mathrm{ml}$ of samples were taken from organic phase and transferred into $1.5 \mathrm{ml}$ vials. For derivatization the solution was stripped under a gentle stream of nitrogen, $10 \mu \mathrm{L}$ of derivatizing agent TMSI and Pyridine (Supelco) and hexane up to $1 \mathrm{ml}$ were added. The solutions were heated at $70^{\circ} \mathrm{C}$ for $30 \mathrm{~min}$. The derivatized samples were analyzed by GC-MSD and the extracted samples were conserved at $-20^{\circ} \mathrm{C}$ in vial with teflon-coated screw caps. The registered mass spectra were compared with those of the spectra library (NIST) of the instrument, and the 
identification of the metabolites was confirmed by injection and analysis of the corresponding standard compound.

\section{Kinetic modeling}

The residual $n$-alkane concentrations as a function of time were modeled according to the Monod-type kinetic models as reported by Simkins and Alexander (1984). In particular, considering the substrate scarce water solubility and the biomass initial concentration (growth viz. exposition runs), the logistic and first-order kinetic models were applied. For logistic model, the maximum specific growth rate, $\mu_{\max }\left(\mathrm{h}^{-1}\right)$, was estimated from the microbial growth curve, plotting the natural logarithm of $\mathrm{OD}_{600}$ vs time and determining the slope of the linear part of the graph (Zhukov et al., 2007). The inverse yield parameter, q (ppm $\mathrm{OD}_{600}^{-1}$ ) (Simkins and Alexander, 1984), was estimated as the ratio of the degraded $n$-alkane to $\mathrm{OD}_{600}$ increase. A non-linear regression was used for the fitting of the logistic model to the experimental data. The goodness of fit was evaluated on the basis of the determination coefficient, the standard error of the estimated parameter and the p-value.

For first-order kinetic model, the natural logarithm of substrate concentration $v s$ time was plotted and the slope of the least-squares-regression line was determined.

\section{Identification and cloning of the alkB gene cluster}

The isolation of the complete coding region of the alkB gene cluster from $R$. opacus R7 was obtained from purified genomic DNA of the strain by PCR-amplification.

To identify the genomic region, two primers (F1, 5'-AA GGCCATGGGGCGTTAGAGCACCGCAGCTAAT-3' and R1, 5'-ACAGCATATGACCTAGCGGGCGGCCGCGACC CG-3') were designed on the basis of the more conserved sequences between the alkB gene cluster of different bacteria belonging to the Rhodococcus genus deposited in Genbank DataBase. It was carried out using the following program: $95^{\circ} \mathrm{C}$ for $3 \mathrm{~min} ; 9^{\circ} \mathrm{C}$ for $30 \mathrm{sec}, 68^{\circ} \mathrm{C}$ for $45 \mathrm{sec}, 72^{\circ} \mathrm{C}$ for 5 min, for 35 cycles; and $72^{\circ} \mathrm{C}$ for $3 \mathrm{~min}$.

DNA fragments were purified from agarose gel by the NucleoSpin Extraction II Kits by Machery and Nagel. The eluted fragment was sequenced by automated sequencing (Eurofins MWG). The nucleotide sequence of the alkB gene cluster of $R$. opacus $\mathrm{R} 7$ was deposited in the GenBank DataBase (KJ573524).

The $3.0 \mathrm{~Kb}$ fragment, containing the alkB gene cluster, was then amplified by PCR using the primers NcoIalkR7 5' -AAGGCCATGGACGTGACGACGTCGGATA TC-3' and NdeI-alkR7 5'-ACAGCATATGACCTAGCG GGCGGCCGCGAC-3' in order to generate the NcoINdeI ends. The $3.0 \mathrm{~Kb}$ fragment was cloned as PCR product into the pDrive vector (Qiagen). The ligation mixture was used to transform E. coli $\mathrm{DH} 5 \alpha$ by electroporation and the recombinant clones were selected on
LB agar supplemented with ampicillin $100 \mu \mathrm{g} / \mathrm{ml}$ and IPTG $1 \mathrm{mM}$ and 5-bromo-4-chloro-3-indolyl- $\beta$-D galactopyranoside (X-Gal) $40 \mu \mathrm{g} / \mathrm{ml}$. White colonies were isolated and plasmid (pDrive-alkR7) of the recombinant clones was extracted and verified with digestion NcoI/NdeI.

\section{Construction of the recombinant strain $R$. erythropolis AP (pTipQT1-alkR7) and activity of the alkB system}

The alkB insert was ligated as NcoI-NdeI fragment into a shuttle-vector E. coli-Rhodococcus, pTipQT1 (Nakashima and Tamura 2004a). The ligation mixture was used to transform E. coli $\mathrm{DH} 5 \alpha$ by electroporation with standard procedures (Sambrook and Russell, 1989) and the recombinant clones were selected on LB agar supplemented with ampicillin $(100 \mu \mathrm{g} / \mathrm{ml})$ at $37^{\circ} \mathrm{C}$. Ampicillin-resistant clones were selected and the recombinant plasmid (pTipQT1alkR7) was isolated. The same recombinant plasmid was used as shuttle-vector to transform others Rhodococcus spp. strains by electroporation. We chose as host Rhodococcus erythropolis AP selected in our laboratory (Maffei, 2004) because the expression of the Ptip system efficiency was more performant in erythropolis species (Nakashima and Tamura, 2004b). Plasmids were introduced into strains of Rhodococcus spp. by electroporation using a Gene Pulser II (Biorad, Italia) set at $2.50 \mathrm{kV}, 600 \Omega, 25 \mu \mathrm{F}$ (Treadway et al., 1999) in presence of about $1 \mu \mathrm{g}$ DNA. Immediately after electroporation, $2.5 \mathrm{ml}$ recovery broth (LB medium with $1.8 \%$ sucrose) were added and cells were incubated at $30^{\circ} \mathrm{C}$ for $4 \mathrm{~h}$. Cells were plated on LB supplemented with tetracycline $25 \mu \mathrm{g} / \mathrm{ml}$ and grown at $30^{\circ} \mathrm{C}$ for 3-4 days. The stability of the recombinant plasmid in the $R$. erythropolis AP was verified after extraction and restriction analysis of the plasmid from all $R$. erythropolis AP (pTipQT1-alkR7) clones. All the clones were able to maintain the recombinant plasmid.

Moreover, before biodegradation experiments, a representative amount of colonies of the recombinant strain underwent the same procedure and we verified the maintaining of the plasmid in the following generations.

Recombinant strain $R$. erythropolis AP (pTipQT1-alkR7) was used for biodegradation experiments in presence of $n$ alkane $\mathrm{C} 12$ to evaluate the activity of the alkB system.

\section{Chemicals}

All chemicals used were of analytical grade. All organic solvents used were high-performance liquid chromatographic (HPLC) grade supplied from Fluka. Naphtalene, $o$-xylene and $n$-alkanes, 1-dodecanol, 2-dodecanol, dodecanoic acid were supplied from Sigma.

\section{Results}

Growth of R. opacus R7 on medium- and long-chain $n$-alkanes Rhodococcus opacus R7 was isolated from a soil contaminated by polycyclic aromatic hydrocarbons, and the strain was able to grow on naphthalene, $o$-xylene (Di 
Gennaro et al., 2001; Di Gennaro et al., 2010) as well as on various medium- and long-chain $n$-alkanes.

The metabolism on $n$-alkanes was investigated in presence of medium- and long-chain $n$-alkanes. Growth of R7 in M9 mineral broth in presence of $n$-hexane (C6), n-octane (C8), n-decane (C10), n-dodecane (C12), $n$-hexadecane (C16), n-eicosane (C20), n-tetracosane (C24), n-hexatriacontane (C36) (1 g/l) supplied as the only carbon and energy source was tested in $96 \mathrm{~h}$. An increasing biomass accumulation was observed by spectrophotometric analysis at $\mathrm{OD}_{600}$ every $24 \mathrm{~h}$. $R$. opacus R7 grew with $n$-alkanes ranging in length from $\mathrm{C} 10$ to $\mathrm{C} 36$, but no growth was observed in the range of C6-C8 n-alkanes (Table 2).

Although $\mathrm{R} 7$ growth on $n$-alkanes ranging in length from C20 to C36 was difficult to determine, due to the low solubility of solid $n$-alkanes in water, a certain growth was observed around the solid $n$-alkane agglomerates formed and on the wall of the flasks. Before the growth measurement, a strong agitation of the flasks was necessary to observe a homogeneous cells suspension (van Beilen et al., 2002).

The capacity of $R$. opacus R7 to degrade $n$-alkanes ranging in length from $\mathrm{C} 12$ to $\mathrm{C} 24$ was investigated as a function of time.

\section{Biodegradation kinetics of medium- and long-chain $n$-alkanes C12-C24}

To investigate the capacity of $R$. opacus $\mathrm{R} 7$ to degrade $n$-alkanes, kinetic runs were performed in M9 mineral medium supplemented with C12, C16, C20, C24 as the sole carbon and energy source; growth was followed at different times up to $72 \mathrm{~h}$ (Figure 1, a, b, c, d). The increase in biomass was quite the same for the four substrates, indeed $\mathrm{OD}_{600}$ reached about 0.5-0.7. GC-MSD analyses of $n$-alkane residues were performed after extraction from broths; the results showed that substrate consumption occurred parallel to biomass increase.

The consumption rate of $\mathrm{C} 12$ was $88 \%$, of C16 was $69 \%$, of $\mathrm{C} 20$ was $51 \%$ and of $\mathrm{C} 24$ it was $78 \%$. The consumption

Table 2 Degradation of $\boldsymbol{n}$-alkanes by Rhodococcus opacus R7

\begin{tabular}{lcc}
\hline $\boldsymbol{n}$-Alkane & Carbon atoms & Rhodococcus opacus R7 \\
\hline Hexane & 6 & - \\
Octane & 8 & - \\
Decane & 10 & + \\
Dodecane & 12 & + \\
Hexadecane & 16 & + \\
Eicosane & 20 & + \\
Tetracosane & 24 & + \\
Hexatriacontane & 36 & + \\
\hline
\end{tabular}

-, no growth; +, growth. of $\mathrm{C} 12$ was higher than longer $n$-alkanes: the decrement of degradation rate of these hydrocarbons seems to be correlated to the length of the aliphatic chain.

Abiotic controls were performed in presence of each hydrocarbon. The amount of abiotic loss was about 20\% for $\mathrm{C} 12$, about $24 \%$ for $\mathrm{C} 16$, about $18 \%$ for $\mathrm{C} 20$, and about $26 \%$ for $\mathrm{C} 24$, respectively.

$n$-Alkane residual concentrations as a function of time followed a logistic curve, typical of a biodegradation process where a scarcely soluble organic compound is degraded by a growing microbial culture. From the experimental data treatment, values of the maximum specific growth rate, $\mu_{\max }$, and of the semisaturation constant, $K_{S}$, were estimated (Table 3 ). As expected, $K_{S}$ increased from $\mathrm{C} 12$ to $\mathrm{C} 24$, indicating a decrease in the biodisponibility of the $n$-alkane for the biomass. On the contrary, $\mu_{\max }$ was almost constant for C12, C16 and $\mathrm{C} 20$ and of the order of $0.015 \mathrm{~h}^{-1}$, while it approached $0.032 \mathrm{~h}^{-1}$ for $\mathrm{C} 24$. This last value could indicate that more enzymatic systems were involved in the degradation of C24 or that a different up-take mechanism could be hypothesized.

\section{Metabolic intermediates of $n$-alkane $\mathrm{C} 12$ degradation}

Metabolic intermediates of $n$-alkanes in $R$. opacus $\mathrm{R} 7$ were determined from cultural broths during the growth on $n$-dodecane as reference substrate, chosen on the basis of the kinetic parameters determined for biodegradation runs. $\mathrm{R} 7$ growth on $\mathrm{C} 12$ was followed during the exposition to the hydrocarbon as a function of time. At time $0 \mathrm{~h}, 3 \mathrm{~h}, 5 \mathrm{~h}, 8 \mathrm{~h}$ and $24 \mathrm{~h}$, culture samples were acidified, extracted, and analyzed by GC-MSD as reported in Material and Methods. Cultural broth analysis showed the presence of 1-dodecanol and the corresponding carboxylic acid (Figure 2) which were identified by comparison with the relative standards. We identified the 1-dodecanol only and not the mixture of 1-dodecanol and 2-dodecanol, as reported in literature for many cases of Rhodococcus strains (Whyte et al., 1998; Whyte et al., 2002). To confirm these data, both 1dodecanol and 2-dodecanol were supplied separately as carbon and energy source and growth was observed only in presence of 1-dodecanol and no growth was observed in presence of 2-dodecanol. Moreover, we observed growth when the dodecanoic acid was supplied as the only carbon and energy source.

\section{Identification and sequencing of the $R$. opacus R7 alkB gene cluster involved in $n$-alkanes degradation}

The alkB gene cluster from $R$. opacus R7 genomic DNA was identified (Figure 3 ) and sequenced. This region was isolated by PCR with primers designed on the basis of the alignment of conserved sequences from the $a l k B$ gene region from different $n$-alkane degrading Rhodococcus 

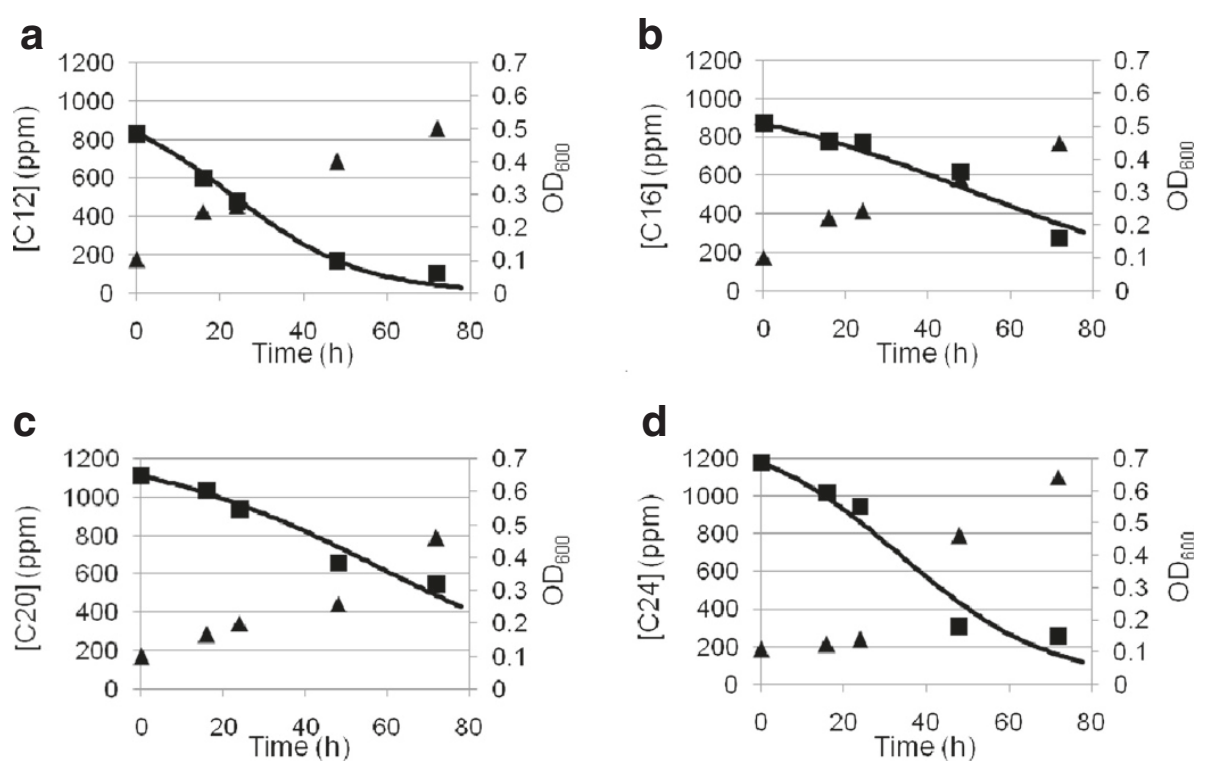

Figure 1 Kinetic analyses of $n$-dodecane (C12) (a), $n$-hexadecane (C16) (b), $n$-eicosane (C20) (c), $n$-tetracosane (C24) (d) degradation in R. opacus R7. Cells of R. opacus R7 were exposed to the $n$-alkane after growth on naphthalene and a flask each day was sacrified for the extraction and the GC-MSD determination of the residual hydrocarbon.

bacteria. The genomic $3.0 \mathrm{~Kb}$ fragment was isolated and sequenced. From the sequence analysis, the covering region contained four consecutive ORFs homologues to the alkB gene cluster components: alkB encoding for an alkane monooxygenase, $r u b A$ encoding for a rubredoxin, $r u b B$ encoding for a second rubredoxin, and rubred encoding for a rubredoxin reductase.

These sequences isolated from R7 strain were compared with the ones of other bacteria belonging to the Rhodococcus genus. In comparison with Rhodococcus opacus B4 (Sameshima et al., 2008), benzene-tolerant capable of growing on $n$-alkanes, alkB gene showed an identity of $94 \%$ (the corresponding protein AlkB 91\%), rubA, rubB, and rubred an identity of $90 \%, 95 \%$ and $86 \%$ (RubA 91\%, RubB 97\%, RubRed 85\%), respectively. In comparison with Rhodococcus sp. BCP1 (Cappelletti et al., 2011), capable of growing on volatile and medium-chain $n$-alkanes, alkB gene presented an identity of $83 \%$ (AlkB $80 \%$ ), rubA, rubB and rubred an

Table 3 Biodegradation kinetic parameters for $\boldsymbol{n}$-alkanes metabolism in $R$. opacus $R 7$

\begin{tabular}{|c|c|c|c|c|c|}
\hline \multicolumn{3}{|c|}{ Substrate consumption } & \multicolumn{3}{|l|}{ Cellular growth } \\
\hline Substrate & $\begin{array}{l}\mu_{\max } / K_{s} \\
(1 / \mathrm{h} \mathrm{ppm})\end{array}$ & $\mathrm{R}^{2}$ & $\mu_{\max }\left(h^{-1}\right)$ & $R^{2}$ & $\mathrm{~K}_{\mathrm{S}}(\mathrm{ppm})$ \\
\hline$\overline{\mathrm{C} 12}$ & $(6.3 \pm 0.3) 10^{-5}$ & 0.988 & $0.013 \pm 0.002$ & 0.972 & 210 \\
\hline C16 & $(3.1 \pm 0.2) 10^{-5}$ & 0.938 & $0.0129 \pm 0.0007$ & 0.997 & 420 \\
\hline C20 & $(2.7 \pm 0.2) 10^{-5}$ & 0.952 & $0.017 \pm 0.004$ & 0.956 & 650 \\
\hline C24 & $(3.9 \pm 0.4) 10^{-5}$ & 0.952 & $0.032 \pm 0.009$ & 0.905 & 810 \\
\hline
\end{tabular}

identity of $86 \%, 84 \%$ and $69 \%$ (RubA 79\%, RubB 84\%, RubRed 60\%), respectively. Compared to Rhodococcus jostii RAH1 (McLeod et al., 2006), able to degrade polychlorinated biphenyls (PCBs), alkB gene presented an identity of $94 \%$ (AlkB 91\%), rubA, rubB and rubred an identity of 99\%, 94\% and 91\% (RubA 98\%, RubB 97\%, RubRed 91\%), respectively.

\section{Construction of the recombinant strain R. erythropolis AP (pTipQT1-alkR7) and activity of the alkB system}

The alkB gene cluster was isolated from R7 genomic DNA as PCR product and cloned into the pDrive vector giving the plasmid pDrive-alkR7. The region was isolated as NcoI/NdeI fragment and cloned into the shuttle-vector E. coli-Rhodococcus $\mathrm{pTipQT1}$. The recombinant plasmid pTipQT1-alkR7 was isolated from E. coli DH5a and transferred into Rhodococcus erythropolis AP, because the Ptip/ regulator system of the shuttle-vector is more efficient in Rhodococcus erythropolis species (Nakashima and Tamura 2004b). In order to verify the expression of the alkB gene cluster under the control of the Ptip/regulator system, experiments with resting cells of Rhodococcus erytropolis

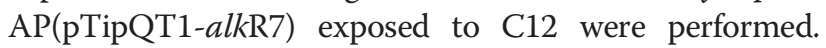
The expression of the alk region was determined comparing the biodegradation kinetics of the recombinant strain $R$. erythropolis AP (pTipQT1-alkR7) with the wild type strain R. erythropolis AP. Results are reported in Figure 4. The percentage of biodegradation in $6 \mathrm{~h}$ was near $80 \%$ in the recombinant strain and $37 \%$ in the wild type strain. From kinetics analysis we can observe that the initial 


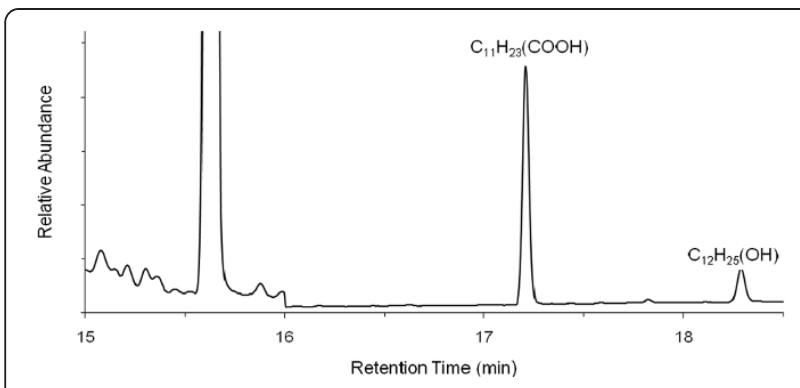

Figure 2 Cultural broth analysis by GC-MSD. Cells of R. opacus R7 were exposed to $n$-dodecane and at different times, the cultural broth were analysed in GC-MSD. The intermediate metabolites identified are reported in the graph.

degradation rate was higher in the recombinant strain with respect to the wild type strain indicating a difference in the activity levels of the alkB system. This difference was confirmed by a statistical test for the comparison of the slopes of the regression lines at 95\% significance level.

\section{Discussion}

In this paper Rhodococcus opacus R7, a strain with a versatile metabolism, was characterized for the ability to degrade variable-chain-length $n$-alkanes.

Many alkane-degrading bacteria have been isolated and the enzyme systems that oxidize $n$-alkanes up to C16 have been characterized (Rojo, 2009; van Beilen and Funhoff, 2007, Wentzel et al., 2007). Long-chain $n$-alkanes are more persistent in the environment than the shorter but few data are available in particular concerning the metabolism of these compounds in Grampositive bacteria (Whyte et al., 2002; Smits et al., 2002; Lo Piccolo et al., 2011).

$R$. opacus $\mathrm{R} 7$ showed the ability to grow on medium and long chain $n$-alkanes ranging from $\mathrm{C} 10$ to C36. Biodegradation kinetics suggested that R7 strain degraded the $n$-alkanes with a lower number of carbon atoms to a greater extent (88\% C12, 69\% C16, 51\% C20, 78\% C24). Moreover, $\mu_{\max }$ was almost constant for $\mathrm{C} 12, \mathrm{C} 16$ and C20 and about $0.015 \mathrm{~h}^{-1}$, while it approached $0.032 \mathrm{~h}^{-1}$ for C24. To our knowledge, no literature data are available concerning specific growth rates on single $n$-alkanes, but only Zhukov et al. reported data in presence of a mixture of $n$-alkanes (Zhukov et al., 2007). The decrement of degradation percentage of these hydrocarbons seems to be inversely correlated to the length of the aliphatic chain as already reported (van Beilen et al., 2003; Lo Piccolo et al., 2011). An exception was C24; in fact, when growing on this hydrocarbon, R7 strain showed a higher increase in $\mathrm{OD}_{600}$, although the degradation percentage was similar to that observed for $\mathrm{C} 12$, and a higher $\mu_{\max }$. These data suggested that other enzymatic systems could be involved in C24 degradation. Another hypothesis could be a different up-take mechanism, supported by the experimental observation of a massive adhesion of R7 cells to C24 powder (van Beilen et al., 2003; Rapp et al., 2003; Lo Piccolo et al., 2011).

\begin{tabular}{c|c|c|c|c|c|c}
1 & 2 & 3 & $4 \mathrm{~Kb}$ \\
$\mid$ & & & & & & \\
\hline
\end{tabular}

Rhodococcus opacus R7

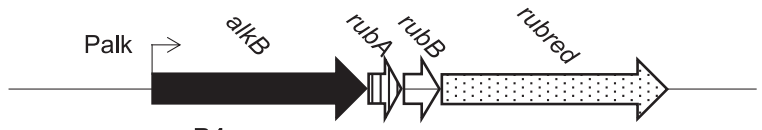

Rhodococcus opacus B4
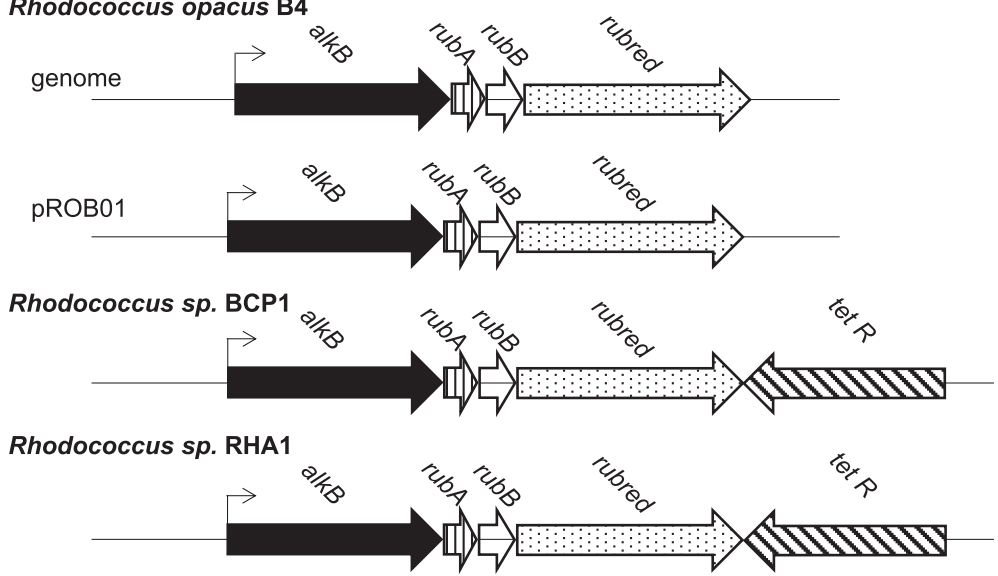

Figure 3 Gene organization of the alkB gene cluster of R. opacus R7 and comparison with equivalent clusters from other alkane-degrading Rhodococcus bacteria. 


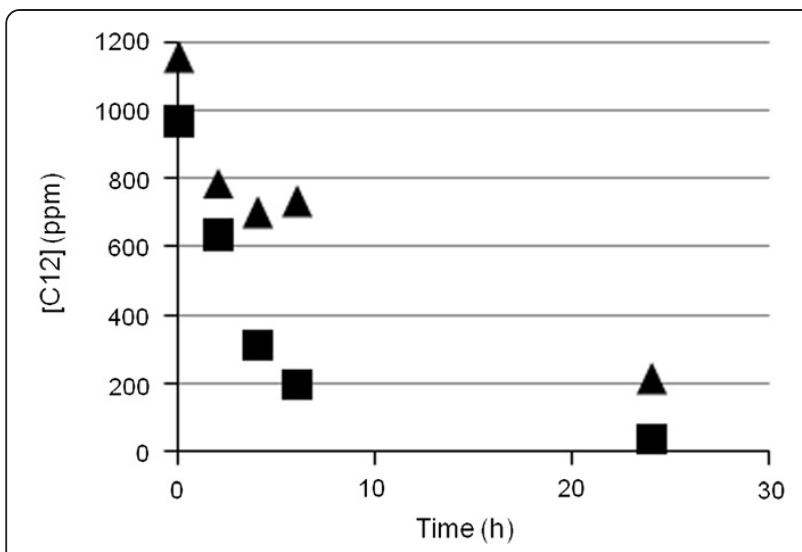

Figure 4 Kinetic analyses of $n$-dodecane degradation in R. erytropolis AP (pTipQT1-alkR7) recombinant strain (square in the graph). Cells of the recombinant strain were grown on rich medium and then, after induction with thiostrepton, were collected and exposed to $n$-dodecane. For comparison, kinetics of $n$-dodecane degradation in $R$. erytropolis AP (triangle in the graph) without the cloned fragment expressing the alkB gene, is also showed.

Many strains from different microbial genera are able to grow on $n$-alkanes. Alkanes are usually activated by a terminal oxidation to the corresponding primary alcohol, which is further oxidized by the alcohol and the aldehyde dehydrogenases to the corresponding acid. The resulting fatty acid enters into the beta-oxidation cycle. In some cases $n$-alkanes are metabolized via terminal as well as subterminal oxidation to the corresponding secondary alcohol. The secondary alcohol is converted to the corresponding ketone which is oxidized by a monooxygenase to an ester that is successively hydrolyzed by an esterase to an alcohol and a fatty acid (van Beilen et al., 2003; Ji et al., 2013). On the basis of the metabolic intermediates determined by the $\mathrm{R} 7$ growth on $\mathrm{C} 12$, our data indicated that $R$. opacus $\mathrm{R} 7$ metabolizes mediumchain $n$-alkanes by the primary alcohol formation because no trace of the secondary alcohol was found and because the strain is not able to grow on this compound. This result highlights a difference in comparison with many Rhodococcus strains in which a mixture of the two alcohols was observed (Whyte et al., 1998 and references therein). In the GC-MSD analysis we also identified the monocarboxylic acid, confirming therefore the activation by a terminal oxidation of the $n$-alkane as reported for Rhodococcus sp. MS11 by Rapp et al., 2003.

Moreover, the alkB gene cluster from $R$. opacus R7 was isolated and its involvement in the $n$-alkane degradation was studied. In this paper we identified the alkB gene cluster including an alkB gene, encoding for an alkane hydroxylase, two rubredoxins $\mathrm{A}$ and $\mathrm{B}$, and a gene encoding for a rubredoxin reductase that are all required in the catalytic process as electron transfer proteins.
Phylogenetic analysis of R7 alkB gene cluster showed a significant similarity with the homologous system of $R$. opacus B4 (Sameshima et al., 2008) and a lower identity with Rhodococcus sp. BCP1 (Cappelletti et al., 2011).

Although four types of $n$-alkane aerobic degradation pathways have been identified to date, the number of alkane hydroxylases that have been isolated, characterized and analyzed by structural biology techniques remains limited. The most widely characterized alkane degradation system is the AlkB of Pseudomonas putida GPo1 (Smits et al., 2002; van Beilen et al., 2003). Researchers have also isolated and cloned novel genes encoding AlkB from bacteria belonging to Rhodococcus genus, such as Rhodococcus opacus B4 (Sameshima et al., 2008) or Rhodococcus sp. Q15 (Whyte et al., 2002), but more information in these bacteria needs to be addressed. Literature data report the involvement of the alkane monoxygenase in the $n$-alkane biodegradation demonstrated by the changing of the GTG coding sequence for the expression in $E$. coli of this enzyme (Sameshima et al., 2008). Other authors were unable to show function heterologous expression of alkB genes in Pseudomonas or $E$. coli expression system, principally because the functional expression requires proper synthesis, correct folding, and proper assembly, and these are not always ensured for rhodococcal proteins (Whyte et al., 2002). On these bases, the alkB region identified from $R$. opacus R7 was cloned for the first time into a shuttlevector E. coli-Rhodococcus and the alkane hydroxylase activity was evaluated in $R$. erythropolis AP. This strain was chosen not only because it belongs to the Rhodococcus genus but also because it belongs to the erythropolis species. In fact, the Ptip/regulator system of the shuttlevector showed the best performance when expressed in erythropolis species as reported by Nakashima and Tamura, 2004b. In this way, we were able to overcome difficulties concerning gene expression in heterologous bacteria. Our results showed an increased biodegradation of $\mathrm{C} 12$ in the recombinant strain $R$. erythropolis AP (pTipQT1-alkR7) in comparison with the wild type strain $R$. erythropolis AP. These data supported the involvement of the alkB gene cluster in the $n$-alkane degradation in R7 strain. Considering the biodegradation kinetics for the C12-C24 substrate range, we can hypothesize that for the medium-chain-length $n$-alkanes an alkB like system plays the main role, while for $n$-alkanes longer than $\mathrm{C} 20$, other alkane hydroxylases could be involved.

\section{Competing interests}

The authors declare that they have no competing interests.

\section{Authors' contributions}

JZ carried out the molecular biology studies and chemical analysis, participated in the sequence alignment and drafted the manuscript. EC participated in the design of the study and performed kinetic analysis. ML 
performed statistical data treatments and interpretation of the data. PDG participated in the design of the study and the coordination and helped to draft the manuscript. All authors read and approved the final manuscript.

\section{Acknowledgment}

We thank Prof. T. Tamura from Okkaido University of Japan to for supplying the shuttle-vector PTipQT1.

\section{Author details}

'Department of Biotechnology and Biosciences, University of Milano-Bicocca, Piazza della Scienza 2, 20126 Milano, Italy. ${ }^{2}$ Department of Earth and Environmental Sciences, University of Milano-Bicocca, Milano, Italy.

\section{Received: 1 September 2014 Accepted: 5 September 2014}

\section{Published online: 30 September 2014}

\section{References}

Alonso H, Roujeinikova A (2012) Characterization and two-dimensional crystallization of membrane component alkB of medium-chain alkane hydroxylase system from Pseudomonas putida GPo1. Appl Environ Microbiol 78:7946-7953

Cappelletti M, Fedi S, Frascari D, Ohtake H, Turner RJ, Zannoni D (2011) Analyses of both the alkB gene transcriptional start site and alkB promoter-inducing properties of Rhodococcus sp. strain BCP1 Grown on n-alkanes. Appl Environ Microbiol 77:1619-1627

Di Gennaro P, Rescalli E, Galli E, Sello G, Bestetti G (2001) Characterization of Rhodococcus opacus R7, a strain able to degrade naphthalene and o-xylene isolated from a polycyclic aromatic hydrocarbon-contaminated soil. Res Microbiol 152:641-651

Di Gennaro P, Terreni P, Masi G, Botti S, De Ferra F, Bestetti G (2010) Identification and characterization of genes involved in naphthalene degradation in Rhodococcus opacus R7. Appl Microbiol Biotechnol 87:297-308

Finnerty WR (1992) The biology and genetics of the genus Rhodococcus. Annu Rev Microbiol 46:193-218

Harayama S, Kasai Y, Hara A (2004) Microbial communities in oil-contaminated seawater. Curr Opin Biotechnol 15:205-241

Ji Y, Mao G, Wang Y, Bartlam M (2013) Structural insights into diversity and nalkane biodegradation mechanisms of alkane hydroxylases. Front Microbiol 4:1-13

Kulakov LA, Delacroix VA, Larkin MJ, Ksenzenko VN, Kulakova AN (1998) Cloning of new Rhodococcus extradiol dioxygenase genes and study of their distribution in different Rhodococcus strains. Microbiology 144:955-963

Larkin MJ, Kulakov LA, Allen CC (2005) Biodegradation and Rhodococcus-masters of catabolic versatility. Curr Opin Biotechnol 16:282-290

Larkin MJ, Kulakov LA, Allen CC (2006) Biodegradation by members of the genus Rhodococcus: biochemistry, physiology, and genetic adaptation. Adv Appl Microbiol 59:1-29

Leahy J, Colwell R (1990) Microbial biodegradation of hydrocarbons in environment. Microbiol Rev 54:305-315

Lo Piccolo L, De Pasquale C, Fodale R, Puglia AM, Quatrini P (2011) Involvement of an alkane hydroxylase system of Gordonia sp. strain SoCg in degradation of solid n-alkanes. Appl Environ Microbiol 77:1204-1213

Maffei F (2004) Individuazione dei fattori che stimolano la biodegradazione di idrocarburi presenti in suoli contaminati. University of Milano-Bicocca, Thesis

Maniatis T, Fritsch EF, Sambrook J (1982) Molecular cloning: a laboratory manual. Cold Spring Harbor Laboratory, Cold Spring Harbor, New York

Margesin R, Labbé D, Schinner F, Greer CW, Whyte LG (2003) Characterization of hydrocarbon-degrading microbial populations in contaminated and pristine alpine soils. Appl Environ Microbiol 69:3085-3092

Martínková L, Uhnáková B, Pátek M, Nešvera J, Křen V (2009) Biodegradation potential of the genus Rhodococcus. Environ Intern 35:162-177

McLeod MP, Warren RL, Hsiao WWL, Araki N, Myhre M, Fernandes C, Miyazawa D, Wong W, Lillquist AL, Wang D, Dosanjh M, Hara H, Petrescu A, Morin RD, Yang G, Stott JM, Schein JE, Shin H, Smailus D, Siddiqui AS, Marra MA, Jones SJM, Holt R, Brinkman FSL, Miyauchi K, Fukuda M, Davies JE, Mohn WW, Eltis LD (2006) The complete genome of Rhodococcus sp. RHA1 provides insights into a catabolic powerhouse. Proc Natl Acad Sci 103:15582-15587

Nakashima N, Tamura T (2004a) A novel system for expressing recombinant proteins over a wide temperature range from 4 to $35^{\circ} \mathrm{C}$. Biotechnol Bioeng 86:136-148
Nakashima N, Tamura T (2004b) Isolation and characterization of a rolling-circle-type plasmid from Rhodococcus erythropolis and application of the plasmid to multiple-recombinant-protein expression. Appl Environ Microbiol 70:5557-5568

Rapp P, Lotte H, Gabriel-Jurgens E (2003) Degradation of alkanes and highly chlorinated benzenes, and production of biosurfactants, by a psychrophilic Rhodococcus sp. and genetic characterization of its chlorobenzene dioxygenase. Microbiology 149:2879-2890

Ratajczak A, Geißdörfer W, Hillen W (1998) Expression of alkane hydroxylase from Acinetobacter sp. strain ADP1 is induced by a broad range of $n$-alkanes and requires the transcriptional activator AlkR. J Bacteriol 180:5822-5827

Rojo F (2009) Degradation of alkanes by bacteria. Environ Microbiol 11:2477-2490

Sambrook J, Russell DW (1989) Molecular cloning. A laboratory manual. Cold Spring Harbor Laboratory, Cold Spring Harbor, New York

Sameshima Y, Honda K, Kato J, Omasa T, Ohtake H (2008) Expression of Rhodococcus opacus alkB genes in anhydrous organic solvents. J Biosci Bioeng 106:199-203

Simkins S, Alexander M (1984) Model for mineralization kinetics with the variable of substrate concentration and population density. Appl Environ Microbiol 47:1299-1306

Smits THM, Balada SB, Witholt B, van Beilen JB (2002) Functional analysis of alkane hydroxylases from Gram-negative and Gram-positive bacteria. J Bacteriol 184:1733-1742

So CM, Young LY (1999) Isolation and characterization of a sulfate-reducing bacterium that anaerobically degrades alkanes. Appl Environ Microbiol 65:2969-2976

Treadway SL, Yanagimachi KS, Lankenau E, Lessard PA, Stephanopoulos G, Sinskey AJ (1999) Isolation and characterization of indene bioconversion genes from Rhodococcus strain 124. Appl Microbiol Biotechnol 51:786-793

van Beilen JB, Funhoff EG (2007) Alkane hydroxylases involved in microbial alkane degradation. Appl Microbiol Biotechnol 74:13-21

van Beilen JB, Smits THM, Whyte LG, Schorcht S, Röthlisberger M, Plaggemeier T, Engesser KH, Witholt B (2002) Alkane hydroxylase homologues in Grampositive strains. Environ Microbiol 4:676-682

van Beilen JB, Li Z, Duetz WA, Smits THM, Witholt B (2003) Diversity of alkane hydroxylase system in the environment. Oil Gas Sc Technol 58:427-440

Van der Meer JR, de Vos WM, Harayama S, Zehnder AJB (1992) Molecular mechanisms of genetic adaptation to xenobiotic compounds. Microbiol Rev 56:677-694

Vidali M (2001) Bioremediation. An overview. Pure Appl Chem 73:1163-1172

Wang W, Shao Z (2013) Enzymes and genes involved in aerobic alkane degradation. Front Microbiol 4:1-7

Wentzel A, Ellingsen TE, Kotlar H-K, Zotchev SB, Throne-Holst M (2007) Bacterial metabolism of long-chain n-alkanes. Appl Microbiol Biotechnol 76:1209-1221

Whyte LG, Hawari J, Zhou E, Bourbonnière L, Inniss WE, Greer CW (1998) Biodegradation of variable-chain-length alkanes at low temperatures by a psychrotrophic Rhodococcus sp. Appl Environ Microbiol 64:2578-2584

Whyte LG, Smits THM, Labbé D, Witholt B, Greer CW, van Beilen JB (2002) Gene cloning and characterization of multiple alkane hydroxylase systems in Rhodococcus strains Q15 and NRRL B-16531. Appl Environ Microbiol 68:5933-5942

Zhukov DV, Murygina VP, Kalyuzhnyi SV (2007) Kinetics of degradation of aliphatic hydrocarbons by bacteria Rhodococcus ruber and Rhodococcus erythropolis. Appl Biochem Microbiol 43:587-592

\section{doi:10.1186/s13568-014-0073-4}

Cite this article as: Zampolli et al:: Biodegradation of variable-chainlength $n$-alkanes in Rhodococcus opacus R7 and the involvement of an alkane hydroxylase system in the metabolism. AMB Express 2014 4:73. 